\title{
Effect of 12-week-long aerobic training programme on body composition, aerobic capacity, complete blood count and blood lipid profile among young women
}

Dorota Kostrzewa-Nowak*1,a , Robert Nowak ${ }^{1, a}$, Zbigniew Jastrzębski², Aleksandra Zarębska² ${ }^{2}$ Marta Bichowska², Izabela Drobnik-Kozakiewicz² ${ }^{2}$ Łukasz Radzimiński², Agata Leońska-Duniec ${ }^{3}$, Krzysztof Ficek ${ }^{3}$, Paweł Cięszczyk ${ }^{2,3}$

1Department of Biochemistry, Faculty of Biology, University of Szczecin, Szczecin, Poland

${ }^{2}$ Faculty of Tourism and Recreation, Gdansk University of Physical Education and Sport, Gdansk, Poland

${ }^{3}$ Faculty of Physical Culture and Health Promotion, University of Szczecin, Szczecin, Poland

apresent address: Faculty of Physical Culture and Health Promotion, University of Szczecin, Szczecin, Poland

*Corresponding author: kostrzewa@univ.szczecin.pl

\section{Abstract}

Background: Numerous data suggest that aerobic-type exercise improves lipoprotein-lipid profiles, cardiorespiratory fitness and body composition in young women. The aim of this study was to evaluate the biological response to high-low impact aerobic fitness among young women.

Materials and methods: Thirty-four young women aged 22 (19-24) years were divided into three groups: underweight $(N=10)$, normal weight $(N=12)$ and overweight $(N=12)$. Aerobic capacity, anthropometry and body composition together with complete blood count and lipid profile were determined before and after completion of a 12-week-long training period.

Results: The training programme caused a significant decrease in weight (by $4.3 \mathrm{~kg}, P=0.003$ ), body mass index (by $1.3 \mathrm{~kg} / \mathrm{m}^{2}, P=0.003$ ), free fat mass (by $2.1 \mathrm{~kg}, \mathrm{P}=0.002$ ), total body water (by $0.4 \mathrm{~kg}, \mathrm{P}=0.036$ ), percentage of fat (by 3 percent points, $P=0.002$ ), all analyzed skinfolds thicknesses, as well as the lipid profile in overweight group, and no changes in normal weight group. Significant changes in weight (by $4.2 \mathrm{~kg}, P=0.005$ ), body mass index (by $0.9 \mathrm{~kg} / \mathrm{m}^{2}, \mathrm{P}=0.005$ ), crus skinfold thickness (by $3.3 \mathrm{~mm}, \mathrm{P}=0.028$ ), and in maximum oxygen uptake (by $2.49 \mathrm{~mL} / \mathrm{kg} / \mathrm{min} ; \mathrm{P}=$ 0.047) were observed among underweight women. No change in total blood count was observed in all groups.

Conclusion: Twelve-week-long fitness training programme of two alternating styles (low and high impact) has a beneficial effect on overweight young women.

Key words: body composition; physical fitness; overweight; women

\section{Introduction}

It is well known that being overweight is one of the first health problems leading to obesity. There is a lot of data indicating that being overweight and obesity are among the most common and serious health problems in modern society $(1,2)$. According to the World Health Organization (1) data, there are about 1.6 billion overweight adults with a body mass index (BMI) above $25 \mathrm{~kg} / \mathrm{m}^{2}$. At least 400 million of them are obese, with a $\mathrm{BMI}$ above $30 \mathrm{~kg} / \mathrm{m}^{2}$. Body fat percentage, as well as BMI, is among the factors responsible for the reduced physical fitness, as confirmed by research conduct- ed on young populations (3-5). Various literature data emphasize that regular exercise is a valuable tool in easing the global burden of chronic disease, including those associated with being overweight and obese (6-9). It is also well known that regular exercise influences glycaemia and triglyceridaemia in healthy individuals (6-9). Literature data confirm that exercise, as well as nutrition and pharmacological agents, can substantially alter postprandial glycaemic and triglyceridaemic responses $(8,9)$. An increase in physical activity level is beneficially associated with health. For example, 
improvement of many health indicators, such as lower blood pressure values, reduced insulin resistance, and normalization of lipid profile is a commonly observed effect among both men and women performing physical exercises $(2,8,10)$.

There are numerous data suggesting that aerobictype exercise improves lipoprotein-lipid profiles, cardiorespiratory fitness and body composition in healthy young women $(9,11-13)$. It is known, that elevated aerobic energy expenditure might be associated with a highly favourable stabilization of most known as traditional, as well as emerging, cardiovascular risk predictors $(6,14)$. One of the example could be the Baduanjin exercise (traditional, and one of the most common, Chinese exercise consisting of eight types of body movements each focusing on different body part. Some data evidence that it could modulate the blood lipid profile by decreasing plasma cholesterol, triglycerides, and low-density lipoprotein cholesterol concentration and increasing plasma high-density lipoprotein cholesterol concentration of non-athletes participants compared to a group of no exercise (9). Moreover, Hurley (12) reported the reduction in triglyceride concentration, but no change in total cholesterol or lipoprotein concentrations in blood of non-athletes participating in aerobic-type exercise training, as well as no changes in any lipids or lipoproteins in a group of inactive controls.

Other form of aerobic exercise is hi-low impact aerobic routine. It is the combination of two different types of aerobic exercises - low and high impact. Low impact style comprises the movements with at least one foot on the floor at all times, whereas high impact styles include running, hopping, jumping with various flight phases (15). Both types of aerobic movements are incorporated with music of variable rhythm intensity (tempo). However, it cannot be defined as a "dance aerobic". There are literature data describing the effect of dance aerobic on heart rate, overall fitness level, blood lipoproteins and body composition (16-18). To our best knowledge, there is still a lack of comprehensive data concerning the effect of hi-low impact aerobic exercise on anthropological, physiological and biochemical parameters, especially in regard of young women with different types of so- matic structure (underweight, normal weight and overweight). We hypothesized that this type of exercise would have beneficial effects on the mentioned parameters in young women. We assume that this impact would vary depending on woman's somatic structure: the greatest impact of the exercise would be observed in the overweight group and it would be different in underweight as well as normal weight group.

Considering the importance of exercise as an effective and attractive tool of weight normalization among young, especially overweight, women, the aim of this study was to evaluate the influence of high-low impact aerobic fitness on body composition and selected physiological parameters, as well as lipid status and complete blood count among young women with different types of somatic structure. We also intended to assess the extent to which the effect on overweight women is different from those of normal and low body weight (low fat). We planned to ensure if 12 weeks of exercise is long enough to observe any heathbeneficial effect, as well.

\section{Materials and methods}

\section{Study design}

In our study, we have determined the body composition variables (weight, BMI), cardiorespiratory fitness measures (maximum oxygen uptake $\left(\mathrm{VO}_{2 \mathrm{max}}\right)$, maximum heart rate $\left(\mathrm{HR}_{\text {max }}\right)$, maximum ventilation $\left(\mathrm{V}_{\text {Emax }}\right)$, anaerobic threshold $\left.\left(\mathrm{VO}_{2} / \mathrm{AT}\right)\right)$, complete blood count, triglycerides (Tg), total cholesterol (Chol), high-density lipoprotein cholesterol (HDL) and low-density lipoprotein cholesterol (LDL) blood concentrations, as well as anthropometric parameters (thoracical, abdominal, subscapular, triceps and crus skinfold thicknesses). The research was conducted on 3 groups of participants: underweight, normal weight and overweight (according to their BMl at the beginning of the experiment) non-smoking women before and after completion of 12-week-long fitness training programme. The study was performed in autumn/ winter (September-December) 2012 in the gym belonging to the Gdansk University of Physical Education and Sport, Gdansk, Poland. 


\section{Subjects}

Thirty-four young women met inclusion criteria for the study. They were recruited from the students of Gdansk University of Physical Education and Sport, Gdansk, Poland after screening of medical history, physical activity as well as weight and height questionnaire. Subjects were also nonsmokers and refrained from taking any medications (e.g. any cardiovascular drugs, oral contraceptives, steroidal anti-inflammatory drugs) or supplements (e.g. containing high amounts of Phenylalanine, L-Carnitine) known to affect metabolism. If case of not obeying the agreed rules, change of medical state (e.g. illness, taking any medications or supplements listed above), or smoking, that subject would be excluded from the experiment.

Based on BMI, according to WHO classification (1), participants were divided into three groups: underweight $\left(B M I<18.50 \mathrm{~kg} / \mathrm{m}^{2}\right)-10$ volunteers, normal weight $\left(18.50-24.99 \mathrm{~kg} / \mathrm{m}^{2}\right)-12$ volunteers and overweight $\left(25.00-29.99 \mathrm{~kg} / \mathrm{m}^{2}\right)-12$ volunteers. Individuals included in the study engaged in a regular physical activity within the last 6 months. They had no history of any metabolic syndrome (as defined by International Diabetes Federation: diabetes, prediabetes, abdominal obesity, high cholesterol and high blood pressure) (19) or cardiovascular diseases (defined by WHO as disorders of the heart and blood vessels) (20). Subjects were recommended to follow their ordinary diet, typical to the last 6 months during the study in general. Each subject had individually calculated energetic balance based on the difference between the calories taken with the food and the calories burned by their physical activity before the training programme. Then, they were instructed to maintain zero balance with the $100 \mathrm{kcal}$ tolerance during the 12 weeks of the programme, however it was not controlled.

The subjects were fully informed of any risks and discomfort associated with the experimental procedures before giving their consent to participate. The study was approved by the Pomeranian Medical University Ethics Committee (Decision no. 09/ $\mathrm{KB} / \mathrm{V} / 2011)$ in accordance with the Helsinki Declaration.

\section{Training programme}

The formal training stage was preceded by a weeklong familiarization stage, in which the examined women exercised 3 times a week for 30 minutes, at an intensity of about $50 \%$ of their $\mathrm{HR}_{\text {max. }}$ The $\mathrm{HR}_{\text {max }}$ was determined using an electronically braked cycle ergometer with gas analyzer (Oxycon Pro, Erich JAEGER GmbH, Hoechberg, Germany). All of the subjects performed a continuous, graded exercise test on cycle ergometer. The test began with 5 minutes of continuous pedalling, with a frequency of 60 revolutions per minute (RPM) and a relative load of $1.2 \mathrm{~W} / \mathrm{kg}$. After this phase, the workload was systematically increased by $15 \mathrm{~W}$ every minute until exhaustion. The effort was interrupted when pedalling frequency declined by $10 \%$, that is, when the pedalling frequency fell below 54 RPM. The heart rate measured at this point was noted as a $\mathrm{HR}_{\text {max }}$.

After that, the formal training began. Each training unit (understood as the gathering of participants to exercise) consisted of a warm-up routine (10 minutes), the main aerobic routine (43 minutes) and stretching and breathing exercises (7 minutes). The main aerobic routine was the combination of two different types of aerobic exercises low and high impact (15). Both types of aerobic movements were incorporated with music of variable rhythm intensity (tempo). A 12-week-long programme of high-low impact aerobics was divided as follows: (i) 3 weeks (9 training units), 60 minutes each, at about $50-60 \%$ of $\mathrm{HR}_{\max }$ tempo 135-140 beats per minute (BPM), (ii) 3 weeks (9 training units), 60 minutes each, at $55-65 \%$ of HRmax tempo 135-140 BPM, (iii) 3 weeks (9 training units), 60 minutes with the intensity of $60-70 \%$ of $\mathrm{HR}_{\text {max }}$, tempo 140-152 BPM, (iv) 3 weeks (9 unit training), 60 minutes with an intensity of $65-75 \%$ of $\mathrm{HR}_{\text {max }}$ tempo 140-152 BPM. All 36 training units were administered and supervised by the same instructor.

\section{Blood sampling}

Fasting blood samples were obtained in the morning from the elbow vein. Blood samples from each participant were taken into two tubes. For bio- 
chemical analyses, a $4.9 \mathrm{~mL}$ S-Monovette tube with ethylenediaminetetraacetic acid ( $\mathrm{K}_{3}$ EDTA; 1.6 mg EDTA/mL blood) and separating gel (SARSTEDT AG \& Co., Nümbrecht, Germany) was used. For complete blood count, a $2.6 \mathrm{~mL}$ S-Monovette tube with $\mathrm{K}_{3}$ EDTA (1.6 mg EDTA/mL blood) (SARSTEDT AG \& Co., Nümbrecht, Germany) was used. Blood samples for biochemical analyses were centrifuged $300 \times g$ for 15 minutes at room temperature in order to receive blood plasma.

\section{Methods}

\section{Laboratory methods}

Biochemical and haematological analyses were preformed before the start of aerobic fitness training programme and repeated at the $12^{\text {th }}$ week of this training programme (after the $36^{\text {th }}$ training unit). The analyses were preformed immediately after the blood collection.

Complete blood count, including white blood cells (WBC), red blood cells (RBC), haemoglobin (HGB), haematocrit (HTC), mean corpuscular volume (MCV), mean corpuscular haemoglobin $(\mathrm{MCH})$, mean corpuscular haemoglobin concentration (MCHC), and platelets total level (PLT) was obtained using Sysmex K-4500 Haematology Analyzer (TOA SYSMEX, Kobe, Japan).

All biochemical analyses were conducted using Random Access Automatic Biochemical Analyzer for Clinical Chemistry and Turbidimetry A15 (BIOSYSTEMS S.A., Barcelona, Spain). Blood plasma was used to determine lipid profile: $\mathrm{Tg}, \mathrm{Chol}, \mathrm{HDL}$ and LDL concentrations. Plasma Tg and Chol concentrations were determined using diagnostic colorimetric enzymatic method according to the manufacturer's protocol (BioMaxima S.A., Lublin, Poland). Manufacturer's declared intra-assay coefficients of variation (CV) of the method were $<2.5 \%$ and $<1.5 \%$ for the $\mathrm{Tg}$ and Chol determinations, respectively. HDL plasma concentration was determined using human anti- $\beta$-lipoprotein antibody and colorimetric enzymatic method according to the manufacturer's protocol (BioMaxima S.A., Lublin, Poland). Manufacturer's declared intra-assay CV of the method was $<1.5 \%$. Plasma concentrations of LDL were determined using a direct meth- od according to the manufacturer's protocol (PZ Cormay S.A., Łomianki, Poland). Manufacturer's declared intra-assay CV of the method was $4.97 \%$. All analysis procedures were verified with the use of multiparameteric control serum (BIOLABO S.A.S, Maizy, France), as well as control serum of normal level (BioNormL) and high level (BioPathL) of lipid profile (BioMaxima S.A., Lublin, Poland).

\section{Aerobic capacity $\left(\mathrm{VO}_{2 \max }, V_{E_{\max }}, \mathrm{VO}_{2} / A T\right)$}

All of the subjects performed a continuous graded exercise test on an electronically braked cycle ergometer with gas analyzer (Oxycon Pro, Erich JAEGER GmbH, Hoechberg, Germany) to determine the maximal oxygen uptake $\left(\mathrm{VO}_{2 \mathrm{max}}\right)$, maximal $\mathrm{CO}_{2}$ production $\left(\mathrm{VCO}_{2 \max }\right)$ and maximum minute ventilation $\left(\mathrm{V}_{\mathrm{Emax}}\right)$. The test began with 5 minutes of continuous pedalling, with a frequency of 60 RPM and a relative load of $1.2 \mathrm{~W} / \mathrm{kg}$. After this phase, the workload was systematically increased by 15 W every minute until exhaustion. The effort was interrupted when pedalling frequency declined by $10 \%$, that is, when the pedalling frequency fell below 54 RPM. The highest value of the oxygen uptake maintained for $15 \mathrm{~s}$ was considered to be the $\mathrm{VO}_{2 \max }$. The anaerobic threshold $\left(\mathrm{VO}_{2} / \mathrm{AT}\right.$; gas exchange anaerobic threshold) values were obtained using the V-slope method (21). Briefly, after measuring participant's $\mathrm{VO}_{2 \max }$ and $\mathrm{VCO}_{2 \max }$ a plot of changes of $\mathrm{VCO}_{2 \max }$ as a function of $\mathrm{VO}_{2 \max }$ is generated. The point, where the change in the slopes occurs because of increased $\mathrm{CO}_{2}$ production connected with lactate accumulation is identified as $\mathrm{VO}_{2} /$ AT value.

\section{Anthropometry and body composition}

Anthropometric measurements were conducted in the morning, in a laboratory room at $20-23^{\circ} \mathrm{C}$. At least, a day before measurement, participants did not perform any training or physical activity and they had been prescribed an easily digestible diet, so as not to aggravate their (digestive) system. Additionally, measurements were done at least $2 \mathrm{~h}$ after eating. The measurements were conducted before and after the completion of 12-week-long training programme. 
Anthropometric measurements were performed using Skinfold Caliper GPM 6100 (GPM-Hautfaltenmessgerät, Siber \& Hegner, Zurich, Switzerland). Anthropometric measurements were conducted by the same researcher, according to conventional criteria and measurement procedures (22). Five skinfold thickness (ST), namely: thoracical, abdominal, subscapular, triceps and crus were measured. Briefly, each of the analyzed skinfold thickness was measured as follow:

- thoracical ST: obliquely, in the middle between the anterior axillary line and the nipple;

- abdominal ST: obliquely, at the half of the distance between the navel and the front upper iliac spine;

- subscapular ST; on the back, below the lower angle of the scapula;

- triceps ST; vertically on the back of the arm, in the middle of its length; with the free lowered upper limb;

- crus ST; vertically in the midline of the posterior surface of the lower leg, below the popliteal fossa; with relaxed muscles of the lower limb.

Weight, BMI, body composition (fat free mass, FFM; percentage of fat, $\mathrm{PE}$; total body water, TBW) as well as basal metabolic rate (BMR) were determined using Body Composition Analyzer Tanita TBF 300M (Tanita, Tokyo, Japan). The analyzer was calibrated prior to each test session in accordance to the manufacturer's guidelines. After participant's data (age, sex and height) input, participant wearing only underwear stood on the scale platform to perform the measurement. The measurement is based on the differences in tissue resistance and conductivity depending on the type of tissue and its degree of hydration.

\section{Statistical analysis}

Since the number of participants in each group was low, all data are presented as median and interquartile range (Q1-Q3), except for the age that is presented as median (min-max). Statistical analyses were performed using STATISTICA (data analysis software system), version 10 software (StatSoft, Inc. (2011)). Significance level of differences observed between analyzed time points (before the start of the training programme vs. after 12 weeks of the training programme) for each participant was calculated using Wilcoxon's matched pairs test. Significance level of differences observed between groups (overweight vs. underweight vs. normal weight) was calculated using Kruskall-Wallis test followed by post-hoc multiple comparisons of mean ranks for all groups. Each time, $\mathrm{P} \leq 0.05$ was considered as a significant difference.

\section{Results}

All women divided into three groups according to BMI values (underweight, normal weight and overweight) completed a prescribed 12-week-long aerobic exercise training programme.

A summary of changes in body composition over the aerobic training period in all studied groups is presented in Table 1. It was found that aerobic exercise caused a significant increase in weight and BMI among underweight women and a significant decrease in those parameters in the overweight female group. It was also found that during the course of the training programme, PE, FFM, and TBW were reduced among overweight women, but not changed among underweight and normal weight ones. Additionally, there were no significant changes in BMR after the end of the training programme in any of studied groups. However comparison of this parameter between studied groups indicated significant differences $(P<0.001)$ both at the beginning and at the end of training programme. Post-hoc multiple comparisons of mean ranks for all groups confirmed, that it was caused by the BMR values in the overweight group ( $\mathrm{P}<0.001$ for overweight vs. underweight, $\mathrm{P}=$ 0.002 for overweight vs. normal weight, and $\mathrm{P}<$ 0.001 for overweight vs. underweight; $P=0.003$ for overweight vs. normal weight at the beginning and at the end of the training programme, respectively).

The combination of two alternating styles (low and high impact) of fitness exercises repeated 3 times a week for 12 weeks was shown to have a high impact on thickness of skinfolds, but only in the overweight female group of participants (Table 1). Significant decreases in the thicknesses of 
the skinfolds were found in this group. Interestingly, in the normal weight group, no significant changes in body composition were found after 12 weeks of training (Table 1).

Analysis of differences of analyzed ST between groups (overweight vs. underweight vs. normal weight) showed that there are significant differences at the beginning of the training programme $(P<0.001$ for thoracical, abdominal, and subscapular ST, $\mathrm{P}=0.002$ for triceps $\mathrm{ST}$, and $\mathrm{P}=0.001$ for crus ST). Post-hoc multiple comparisons of mean ranks for all groups indicated that in most cases the overweight group was responsible for those differences. After the completion of 12-week-long fitness training, there were no differences in thoracical, triceps, and crus ST between analyzed groups. Additionally, post-hoc analysis indicated that, in case of subscapular ST, the difference was significant only because of the difference between overweight and underweight group $(P=0.028)$.

Table 2 presents cardiorespiratory fitness measures over the aerobic training period in all studied groups. In terms of cardiorespiratory fitness variables, a significant increase was found only in $\mathrm{VO}_{2 \max }$ among underweight women and $\mathrm{V}_{\text {Emax }}$ in overweight group. Interestingly, cardiorespiratory fitness variables did not indicate statistically significant change in the normal weight group over the course of the training programme.

Our study showed that the combination of two alternating styles, repeated 3 times a week for 12 weeks had no impact on complete blood count in

TABLE 1. The impact of 12-week-long aerobic training programme on body composition among underweight, normal weight and overweight young women.

\begin{tabular}{|c|c|c|c|c|c|c|c|c|c|}
\hline \multirow{2}{*}{$\begin{array}{l}\text { Training } \\
\text { programme }\end{array}$} & \multicolumn{3}{|c|}{ Underweight women } & \multicolumn{3}{|c|}{$\begin{array}{l}\text { Normal weight women } \\
\qquad N=12\end{array}$} & \multicolumn{3}{|c|}{$\begin{array}{l}\text { Overweight women } \\
\qquad N=12\end{array}$} \\
\hline & Before & After & $\mathbf{P}$ & Before & After & $\mathbf{P}$ & Before & After & $\mathbf{P}$ \\
\hline Age (year) & \multicolumn{2}{|c|}{$21(19-24)$} & / & \multicolumn{2}{|c|}{$22(19-23)$} & & \multicolumn{2}{|c|}{$22(19-23)$} & / \\
\hline Height (cm) & \multicolumn{2}{|c|}{$171.0(166.0-174.0)$} & I & \multicolumn{2}{|c|}{164.5 (163.0-168.5) } & & \multicolumn{2}{|c|}{$163.5(159.9-167.0)$} & l \\
\hline Weight (kg) & $51.5(49.0-52.9)$ & $55.7(51.3-56.6)$ & $0.005^{*}$ & $57.2(55.4-61.8)$ & $58.1(55.3-60.7)$ & 0.754 & $69.7(67.0-71.7)$ & $65.4(62.5-67.9)$ & $0.003^{*}$ \\
\hline BMI $\left(\mathbf{k g} / \mathbf{m}^{2}\right)$ & $17.9(17.5-18.1)$ & $18.8(18.5-19.3)$ & $0.005^{*}$ & $21.3(20.6-22.1)$ & $21.4(20.4-22.2)$ & 0.239 & $26.0(25.8-27.4)$ & $24.7(24.1-24.9)$ & $0.003^{*}$ \\
\hline FFM (kg) & $43.7(41.9-45.0)$ & $44.0(42.7-45.8)$ & 0.475 & $44.3(43.5-46.1)$ & $44.6(43.5-46.7)$ & 0.784 & $48.3(45.6-50.1)$ & $46.2(43.9-48.2)$ & $0.002^{*}$ \\
\hline TBW (kg) & $32.0(30.7-32.9)$ & $32.2(30.9-33.5)$ & 0.878 & $32.5(31.8-33.7)$ & $32.7(31.8-34.2)$ & 0.754 & $35.3(33.6-36.7)$ & $34.9(33.4-36.0)$ & $0.036^{*}$ \\
\hline PE (\%) & $20(16-22)$ & $18(15-20)$ & 0.093 & $24(21-26)$ & $23(20-26)$ & 0.255 & $30(29-32)$ & $27(26-28)$ & $0.002^{*}$ \\
\hline BMR (kJ) & $\begin{array}{c}5877 \\
(5676-5981)\end{array}$ & $\begin{array}{c}5879 \\
(5604-5920)\end{array}$ & 0.333 & $\begin{array}{c}5913 \\
(5814-6090)\end{array}$ & $\begin{array}{c}5908 \\
(5824-6097)\end{array}$ & 0.410 & $\begin{array}{c}6325 \\
(6123-6424)\end{array}$ & $\begin{array}{c}6271 \\
(6119-6426)\end{array}$ & 0.374 \\
\hline $\begin{array}{l}\text { Thoracical } \\
\text { ST }(\mathrm{mm})\end{array}$ & $7.8(5.8-9.8)$ & $7.7(6.2-15.4)$ & 0.386 & $10.5(9.2-11.7)$ & $9.8(8.1-13.0)$ & 0.875 & $15.2(14.9-18.9)$ & $12.3(9.4-13.7)$ & $0.002^{*}$ \\
\hline $\begin{array}{l}\text { Abdominal } \\
\text { ST }(\mathrm{mm})\end{array}$ & $11.0(9.0-16.0)$ & $12.3(10.0-19.0)$ & 0.575 & $17.7(14.9-18.3)$ & $14.5(11.5-17.6)$ & 0.099 & $25.6(22.9-28.2)$ & $21.0(18.6-22.2)$ & $0.002 *$ \\
\hline $\begin{array}{l}\text { Subscapular } \\
\text { ST }(\mathbf{m m})\end{array}$ & $9.7(7.4-11.2)$ & $9.0(8.0-13.4)$ & 0.799 & $13.1(11.8-14.9)$ & $11.5(9.9-17.0)$ & 0.583 & $19.4(16.0-24.0)$ & $15.6(13.0-19.3)$ & $0.002^{*}$ \\
\hline $\begin{array}{l}\text { Triceps ST } \\
(\mathbf{m m})\end{array}$ & $5.0(4.6-7.0)$ & $6.5(5.0-14.8)$ & 0.308 & $7.6(5.1-11.4)$ & $7.1(5.7-10.2)$ & 0.906 & $12.2(10.5-14.9)$ & $10.7(8.2-12.7)$ & $0.041^{*}$ \\
\hline Crus ST (mm) & $4.8(3.0-6.2)$ & $8.1(5.0-11.2)$ & $0.028^{*}$ & $7.8(4.2-11.7)$ & $11.6(9.6-13.0)$ & 0.059 & $13.4(11.3-15.9)$ & $11.5(9.3-14.9)$ & $0.023^{*}$ \\
\hline
\end{tabular}

Data are presented as median (interquartile range), age is presented as median (min-max).

BMI - body mass index; FFM - fat free mass; TBW - total body water; PE - percentage of fat; BMR - basal metabolic range; ST skinfold thickness.

The significance levels of the differences observed between analysed time-points were assessed using Wilcoxon's matched pairs test.

*difference statistically significant. 
underweight, normal weight and overweight young women (Table 3). On the other hand, changes in lipid profile among overweight partici- pants were found at the end of aerobic training period. The baseline values of Tg blood concentrations within the recommended values $(<1.7$

TABLE 2. The effect of aerobic-type exercise training on cardiorespiratory fitness measures (before and after the training programme).

\begin{tabular}{|c|c|c|c|c|c|c|c|c|c|}
\hline \multirow[t]{2}{*}{$\begin{array}{l}\text { Training } \\
\text { programme }\end{array}$} & Under & $\begin{array}{l}\text { veight wome } \\
N=10\end{array}$ & & \multicolumn{3}{|c|}{$\begin{array}{l}\text { Normal weight women } \\
\qquad N=12\end{array}$} & \multicolumn{3}{|c|}{$\begin{array}{l}\text { Overweight women } \\
\qquad \mathbf{N}=12\end{array}$} \\
\hline & Before & After & $\mathbf{P}$ & Before & After & $\mathbf{P}$ & Before & After & $\mathbf{P}$ \\
\hline $\begin{array}{l}\mathrm{VO}_{2 \max }(\mathrm{mL} / \\
\mathrm{kg} / \mathrm{min})\end{array}$ & $\begin{array}{c}36.85 \\
(35.15-39.04)\end{array}$ & $\begin{array}{c}39.34 \\
(34.78-43.13)\end{array}$ & $0.047^{*}$ & $\begin{array}{c}32.45 \\
(29.46-37.32)\end{array}$ & $\begin{array}{c}35.03 \\
(31.18-40.25)\end{array}$ & 0.099 & $\begin{array}{c}32.38 \\
(28.04-35.55)\end{array}$ & $\begin{array}{c}33.20 \\
(29.08-35.79)\end{array}$ & 0.814 \\
\hline $\begin{array}{l}V_{\text {Emax }} \\
\text { (L/min) }\end{array}$ & $\begin{array}{c}79.27 \\
(63.06-90.77)\end{array}$ & $\begin{array}{c}84.90 \\
(77.75-107.70)\end{array}$ & 0.059 & $\begin{array}{c}74.22 \\
(68.08-89.98)\end{array}$ & $\begin{array}{c}78.73 \\
(71.54-88.98)\end{array}$ & 0.209 & $\begin{array}{c}68.41 \\
(65.73-69.84)\end{array}$ & $\begin{array}{c}81.53 \\
(79.00-95.02)\end{array}$ & $0.002^{*}$ \\
\hline $\begin{array}{l}\text { HR } R_{\max } \text { (beats/ } \\
\text { min) }\end{array}$ & 186 (183-189) & 187 (184-194) & 0.192 & $192(185-197)$ & 190 (184-197) & 0.401 & $188(185-192)$ & 187 (183-192) & 0.666 \\
\hline $\begin{array}{l}\mathrm{VO}_{2} / \mathrm{AT} \\
\text { (mL/kg/min) }\end{array}$ & $\begin{array}{c}29.88 \\
(28.14-30.81)\end{array}$ & $\begin{array}{c}29.64 \\
(25.34-32.47)\end{array}$ & 0.838 & $\begin{array}{c}25.01 \\
(21.53-26.19)\end{array}$ & $\begin{array}{c}28.22 \\
(24.81-30.23)\end{array}$ & 0.099 & $\begin{array}{c}25.57 \\
(23.11-28.36)\end{array}$ & $\begin{array}{c}23.63 \\
(22.34-26.87)\end{array}$ & 0.346 \\
\hline
\end{tabular}

Data are presented as median (interquartile range).

$\mathrm{VO}_{2 \max }$ - maximum oxygen uptake; $\mathrm{V}_{\mathrm{Emax}}$ - maximum minute ventilation; $\mathrm{HR}_{\max }$ - maximum heart rate; $\mathrm{VO}_{2} / \mathrm{AT}$ - anaerobic threshold The significance levels of the differences observed between analysed time-points were assessed using Wilcoxon's matched pairs test.

*difference statistically significant.

TABLE 3. The impact of 12 weeks of aerobic training programme on complete blood count and blood lipid profile in underweight, normal weight and overweight young women.

\begin{tabular}{|c|c|c|c|c|c|c|c|c|c|}
\hline \multirow{3}{*}{$\begin{array}{l}\text { Training } \\
\text { programme }\end{array}$} & \multicolumn{3}{|c|}{ Underweight women } & \multicolumn{3}{|c|}{ Normal weight women } & \multicolumn{3}{|c|}{ Overweight women } \\
\hline & \multicolumn{3}{|c|}{$\mathbf{N}=10$} & \multicolumn{3}{|c|}{$N=12$} & \multicolumn{3}{|c|}{$N=12$} \\
\hline & Before & After & $\mathbf{P}$ & Before & After & $\mathbf{P}$ & Before & After & $\mathbf{P}$ \\
\hline WBC (109/L) & $5.7(5.2-6.3)$ & $5.9(5.0-7.3)$ & 0.284 & & $5.8(5.0-6.6)$ & 0.062 & $5.8(5.0-7.9)$ & $5.5(4.8-6.8)$ & 0.477 \\
\hline $\operatorname{RBC}\left(10^{12} / \mathrm{L}\right)$ & $4.62(4.44-4.75)$ & $4.48(4.24-4.62)$ & 0.074 & $3(4.23-4.59)$ & $4.55(4.36-4.74)$ & 0.209 & $4.43(4.19-4.75)$ & $4.40 / 4.15$ & .239 \\
\hline HGB & 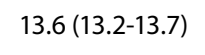 & . & 3 & 2112.9 & (5) & 28 & 8) & $13.4(12.5-14.0)$ & .789 \\
\hline HCT & ) & $39(39-41)$ & 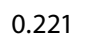 & ) & ) & 1 & 39 & 40 & .698 \\
\hline MCV (fL) & $87.1(86.3-88.7)$ & $88.5(86.4-91.5)$ & 0.308 & $88.0(85.4-90.4)$ & $89.0(86.9-91.7)$ & 0.239 & $88.1(86.2-91.6)$ & $88.2(84.8-92.3)$ & 0.367 \\
\hline MCH (fmol) & $29.2(28.7-29.8)$ & $9.7(28.1$ & 0.799 & $30.1(29.3-31.0)$ & $29.8(29.3-30.6)$ & 0.099 & $30.1(28.7-31.5)$ & $29.8(28.3-31.7)$ & 0.142 \\
\hline MCHC (nr & $33.4(32.7-33.8)$ & $3.2(32.4-34.1)$ & 0.183 & $33.9(33.4-34.4)$ & $33.5(33.2-34.1)$ & 0.168 & $34.0(33.1-34.6)$ & $33.7(32.8-34.4)$ & 0.625 \\
\hline PLT (109/L) & $249(232-282)$ & $258(239-275)$ & 0.575 & 200120200 & 1 & 0.158 & $235(226-268)$ & $242(210-279)$ & 0.814 \\
\hline $\operatorname{Tg}(\mathrm{mmol} / \mathrm{L})$ & $1.01(0.85-1.07)$ & $88(0.76-0.96)$ & 0.398 & $.94(0.84-1.18)$ & $0.66(0.62-0.97)$ & 0.138 & $1.26(1.15-1.33)$ & $0.86(0.66-0.96)$ & $0.003^{*}$ \\
\hline Chol (mmc & $4.78(4.29-4.99)$ & $4.33(4.19-4.68)$ & 0.139 & $4.48(4.26-4.77)$ & $4.45(4.11-4$. & 0.136 & $5.22(4.93-6.13)$ & $4.21(3.93-4.55)$ & $0.003^{*}$ \\
\hline HDL (mmol/L) & $1.67(1.62-1.75)$ & $1.63(1.47-1.90)$ & 0.387 & $1.79(1.65-1.92)$ & $1.52(1.26-2.02)$ & 0.091 & $1.70(1.40-2.07)$ & $1.52(1.36-1.63)$ & $0.026^{*}$ \\
\hline LDL (mmol/L) & $2.45(2.17-2.71)$ & $2.18(2.05-2.33)$ & 0.234 & $2.24(2.10-2.50)$ & $2.15(1.93-2.28)$ & 0.074 & $2.93(2.44-3.34)$ & $2.15(1.88-2.35)$ & $0.012^{*}$ \\
\hline
\end{tabular}

Data are presented as median (interquartile range).

WBC - white blood cells; RBC - red blood cells; HGB - haemoglobin; HTC - haematocrit; MCV - mean corpuscular volume; MCH mean corpuscular haemoglobin; MCHC - mean corpuscular haemoglobin concentration; PLT - platelets; Tg - triglycerides; Chol total cholesterol; HDL - high-density lipoprotein cholesterol; LDL - low-density lipoprotein cholesterol.

The significance levels of the differences observed between analysed time-points were assessed using Wilcoxon's matched pairs test.

*difference statistically significant. 
$\mathrm{mmol} / \mathrm{L}$ ) in all studied groups of participants. The Chol and LDL concentrations were also within the recommended values $(<5.2 \mathrm{mmol} / \mathrm{L},<2.59$ $\mathrm{mmol} / \mathrm{L}$ for Chol and LDL, respectively) among underweight and normal weight women, yet HDL concentrations in all studied groups were slightly higher than the upper range of reference values (0.91-1.56 $\mathrm{mmol} / \mathrm{L})$. In the overweight women group Chol and LDL were above the upper range of recommended values. After the studied training programme, all analyzed lipid profile parameters were significantly lower in the overweight group (Table 3).

\section{Discussion}

Our study showed that the combination of two alternating styles (low and high impact) of exercises repeated 3 times a week for 12 weeks had a high impact on studied body composition parameters in the overweight group of young women, and completely no influence on these parameters in the normal weight group. The changes in weight, $\mathrm{BMI}$, crus skinfold thickness and $\mathrm{VO}_{2 \max }$ occurred in the underweight group. It supports our assumption that 12-week-long exercise programme may be sufficient for achieving beneficial effect as well as that this effect varies depending on the somatic built of the subject. Significant reduction in weight, BMI, FFM, TBW, and PE was noticed in case of overweight group, whereas only increase in weight, and BMI was observed among underweight women after the training programme. The increase in weight (and consequently in BMI) of underweight women is caused rather by the fact that they had calculated energetic balance (based on the difference between the calories taken with the food and the calories burned by their physical activity before the training programme) than the exercise itself. It proves that properly calculated caloric intake is needed in achieving and maintaining appropriate weight. Various literature data evidence that the impact of a physical training programme on body composition is related to differential responses in resting metabolic rate or energy expenditure associated with age, sex and type of training programme (23-25). We found signifi- cant reductions in thickness of all examined skinfolds in overweight group after 12 weeks of highlow impact aerobic fitness. Significant changes in body composition after 12 weeks of aerobic exercises were also found by Sanal et al. (26). They compared aerobic exercises (briskly walking outdoor and 15 minutes of exercising on cycle ergometer with the intensity of $50-85 \%$ of $\mathrm{HR}_{\text {max }}$ ) and combined aerobic resistance exercises (aerobic exercises plus additional exercises of upper- and lowerbody large muscles groups two days a week) among 65 participants randomly divided into those groups ( $33+32$ participants, respectively). Cullinen and Caldwell (27) evidenced that a moderate-intensity, progressive resistance weight training programme performed for 12 weeks ( 2 sessions per week, 6 types of lifting exercises per session) caused increases in FFM and strength in untrained young women. Twenty study women (young, untrained) and 10 control ones participated in that study (27). Interestingly, it was found in our study that a 12-week-long aerobic exercise programme caused a decrease in PE and FFM in overweight women, yet there were no changes in PE and FFM in the normal weight, as well as underweight female group. The differences between those findings result from different types of training and training loads. Nevertheless, the values of FFM found by Cullinen and Caldwell (27) and in our study (in case of overweight women) after the completion of the training programme were almost identical $(46.2 \pm 6.0 \mathrm{~kg}$ and 46.2 (43.9-48.2) $\mathrm{kg}$ as found by Cullinen and Caldwell and in our study, respectively). The same situation is in regard of PE (27.2 \pm 2.6 and 27 (26-28) as found by Cullinen and Caldwell and in our study, respectively).

It was found in our experiment that BMR was higher in the overweight group in comparison to the normal weight, as well as underweight group, both before the start and after the 12 week training programme. These results are in line with Butte et al. (23) who also found that BMR in overweight women was higher than in underweight and normal weight ones. They analysed BMR level of women in reproductive age in the study including 116 physically active (20-30 min of moderate exercise at least 3 times a week) women (13 under- 
weight, 70 normal weight, and 33 overweight) aged 18-40 years.

We observed that changes in body compositions appear together with a significant decrease in triglycerides and total cholesterol blood concentrations as well as HDL and LDL cholesterol concentration in the overweight group. The observed effect can be explained by an increase in energy consumption and achieving an 'energy expenditure threshold' during physical effort by this group of participants. The results of our study are in line with data summarized by Gibala and McGee (28), although they studied short-term and high-intensity interval training (six sessions of high-intensity interval training over 2 weeks or a total of approx. 15 min of very intense, approx. $600 \mathrm{~kJ}$, exercise). Gibala and McGee's studies included both men and women, aged 21-27 years, typically 8 subjects in training and the same number of participants in control group. Moreover, it is known that aerobic energy expenditure might be associated with a highly favourable stabilization of most traditional and emerging cardiovascular risk predictors $(14,29)$. However, in underweight and normal weight groups we did not observe those changes.

It is well known that oxygen transport to skeletal muscles via the cardiovascular system, as well as oxygen consumption is a key factor of aerobic capacity not only in athletes (30). Although the combination of two alternating styles (low and high impact) repeated 3 times a week for 12 weeks influenced the self-declared well-being of all the young women, there were no changes in other studied cardiorespiratory fitness measures over the aerobic training period. This might be related to the lack of change in complete blood count of all studied groups (values found after the training programme were compared to the baseline values determined at the beginning of the training programme). The correlation between $\mathrm{O}_{2}$ transport capacity and aerobic performance, as well as total $\mathrm{Hb}$ and maximal $\mathrm{O}_{2}$ uptake in athletes is well described (30). On the other hand, it should be pointed out that differences in complete blood count described in athletes (30) are mainly biological adaptive factors in response to long-term physical effort. In light of this, the studied training pro- gramme was not long or intensive enough to influence complete blood count in non-athlete participants. Additionally, some literature data suggest that 6-month-long aerobic exercise training among non-athlete females reduced total white blood cells (WBC) and neutrophil counts in overweight/obese postmenopausal women, especially in case of women affected by systemic low grade inflammation (29). The study was performed with 464 sedentary postmenopausal overweight/obese (BMI 25.0-43.0 kg/m²) women (45-75 years of age) that were randomized into a control group (no-exercise) and 3 exercise groups differing in the dose of energy expenditure. The exercise consisted of alternating sessions of treadmill walking and semirecumbent cycle ergometry, while control group was asked to maintain their typical level of physical activity (29).

Lower performance in physical fitness tests among overweight and obese women (3-5) suggests that there is a need to propose efficient exercise fitness training programme. That is why the intensity and strength of training programme should be adapted to the specific needs of participants. We suggest that proper aerobic-type exercises may not only allow body composition improvement and achievement of the 'energy expenditure threshold' needed to regulate one's lipid profile, but also an interesting form of physical recreations for overweight women.

The most important value of this study is a comprehensive approach that was undertaken. We assessed the influence of hi-low aerobic fitness training on the level of analyzed chosen anthropological, physiological and biochemical parameters in women with different types of somatic built (underweight, normal weight and overweight). We have shown in our study that the effect is significant in case of overweight women, but also the extent to which it is different from those of normal and low body weight (low fat). We also provide the evidence that 12 weeks of exercise is long enough to observe heath-beneficial effect, at least in case of overweight group.

The main limitation of the study is a small group of participants and lack of obese (BMl $>30 \mathrm{~kg} / \mathrm{m}^{2}$ ) 
women. We also did not control participants' diet and relied only on the answers put in the questionnaire that sometimes may not be true. We believe that research including more women, but also men, from larger area (not only Gdansk, Poland), conducted for a longer time could provide more interesting and reliable data on the influence of two alternating styles (low and high impact) of exercises on participants' body composition and lipid profile.

\section{Conclusion}

In conclusion, we provide evidence that 12-weeklong fitness training programme of two alternating styles (low and high impact) has beneficial effect on overweight women. It reduces not only body mass but also number of body composition

\section{References}

1. WHO. Obesity: preventing and managing the global epidemic. Report of a WHO consultation. World Health Organ Tech Rep Ser 2000;894:1-253.

2. Church TS, LaMonte MJ, Barlow CE, Blair SN. Cardiorespiratory fitness and body mass index as predictors of cardiovascular disease mortality among men with diabetes. Arch Intern Med 2005;165:2114-2120. http://dx.doi.org/10.1001/ archinte.165.18.2114.

3. Artero EG, España-Romero V, Ortega FB, Jiménez-Pavón $D$, Ruiz JR, Vicente-Rodríguez $G$, et al. Health-related fitness in adolescents: Underweight, and not only overweight, as an influencing factor. The AVENA study. Scand J Med Sci Sports 2010;20:418-27. http://dx.doi.org/10.1111/j.16000838.2009.00959.x.

4. Mak KK, Ho SY, Lo WS, Thomas GN, McManus AM, Day JR, Lam TH. Health-related physical fitness and weight status in Hong Kong adolescents. BMC Public Health 2010;10:88. http://dx.doi.org/10.1186/1471-2458-10-88.

5. Nikolaidis PT. Body mass index and body fat percentage are associated with decreased physical fitness in adolescent and adult female volleyball players. J Res Med Sci 2013;18:22-6.

6. Bajpeyi S, Reed MA, Molskness S, Newton C, Tanner CJ, McCartney JS, Houmard JA. Effect of short-term exercise training on intramyocellular lipid content. Appl Physiol Nutr Metab 2012;37:822-8. http://dx.doi.org/10.1139/ h2012-051.
(BMI, FFM, TBW, PE) and anthropological (thoracical, abdominal, subscapular, triceps and crus skinfolds thicknesses) as well as lipid profile (TG, $\mathrm{CH}$, $\mathrm{HDL}-\mathrm{CH}$, LDL-CH) parameters. Therefore, we recommend this kind of activity to overweight young women willing to lose weight and to reduce the risk of a variety of disorders.

\section{Acknowledgments}

The authors would like to thank all individuals who volunteered to participate in the study. The study was supported by National Science Centre (grant no. 2012/07/B/NZ7/01155).

\section{Potential conflict of interest}

None declared.

7. Centers for Disease Control and Prevention (CDC). Vital signs: prevalence, treatment, and control of high levels of low-density lipoprotein cholesterol_-United States, 19992002 and 2005-2008. Morbidity and Mortality Weekly Report 2011;60:109-14.

8. Haxhi J, Scotto di Palumbo A, Sacchetti M. Exercising for metabolic control: is timing important? Ann Nutr Metab 2013;62:14-25. http://dx.doi.org/10.1159/000343788.

9. Mei L, Chen $Q$, Ge L, Zheng G, Chen J. Systematic review of chinese traditional exercise baduanjin modulating the blood lipid metabolism. Evid Based Complement Alternat Med 2012;2012:282131. http://dx.doi. org/10.1155/2012/282131.

10. Hashimoto S, Hayashi S, Yoshida A, Naito M. Acute effects of postprandial aerobic exercise on glucose and lipoprotein metabolism in healthy young women. J Atheroscler Thromb 2013;20:204-213. http://dx.doi.org/10.5551/ jat.14639.

11. Di Blasio A, Izzicupo P, D'Angelo E, Melanzi S, Bucci I, Gallina S, et al. Effects of Patterns of Walking Training on Metabolic Health of Untrained Postmenopausal Women. J Aging Phys Act 2014;22:482-9. http://dx.doi.org/10.1123/ JAPA.2013-0043.

12. Hurley BF. Effects of resistive training on lipoprotein-lipid profiles: a comparison to aerobic exercise training. Med Sci Sports Exerc 1989;21:689-93. http://dx.doi. org/10.1249/00005768-198912000-00012. 
13. LeMura LM, von Duvillard SP, Andreacci J, Klebez JM, CheIland SA, Russo J. Lipid and lipoprotein profiles, cardiovascular fitness, body composition, and diet during and after resistance, aerobic and combination training in young women. Eur J Appl Physiol 2000;82:451-8. http://dx.doi. org/10.1007/s004210000234.

14. Lippi G, Schena F, Salvagno GL, Montagnana M, Ballestrieri F, Guidi GC. Comparison of the lipid profile and lipoprotein(a) between sedentary and highly trained subjects. Clin Chem Lab Med 2006;44:322-6. http://dx.doi. org/10.1515/CCLM.2006.056.

15. De Angelis $M$, Vinciguerra G, Gasbarri A, Pacitti C. Oxygen uptake, heart rate and blood lactate concentration during a normal training session of an aerobic dance class. Eur $\mathrm{J}$ Appl Physiol Occup Physiol 1998;78:121-7. http://dx.doi. org/10.1007/s004210050396.

16. Schiffer T, Schulte S, Sperlich B. Aerobic Dance: Health and Fitness Effects in Middle-Aged Premenopausal Women. JEPonline 2008; 11:25-33.

17. Koltyn KF, Morgan WP. Efficacy of perceptual versus heart rate monitoring in the development of endurance. $\mathrm{Br}$ J Sports Med. 1992;26:132-4. http://dx.doi.org/10.1136/ bjsm.26.2.132.

18. Jakubec A, Stejskal P, Kováčová L, Elfmark M, Řehová I, Botek $M$, Petr $M$. Changes in heart rate variability after a six month long aerobic dance or step-dance programme in women 40-65 years old: the influence of different degrees of adherence, intensity and initial levels. Acta Univ Palacki Olomuc, Gymn. 2008;38:35-44.

19. The IDF consensus worldwide definition of the metabolic syndrome [Electronic version] Available at: http://www.idf. org/metabolic-syndrome. Accessed July 24th, 2014.

20. WHO. Cardiovascular diseases. Available at: http://www. who.int/topics/cardiovascular_diseases/en/. Accessed July 24th, 2014.
21. Beaver WL, Wassermann K, Whipp BJ. A new method for detecting anaerobic threshold by gas exchange. J. Appl Physiol 1986;60:2020-7.

22. Malinowski A, Strzałko J (editors); [Antropologia]. PWN, Warszawa-Poznań; 1985. (in Polish).

23. Butte NF, Treuth MS, Mehta NR, Wong WW, Hopkinson JM, Smith EO. Energy requirements of women of reproductive age. Am J Clin Nutr 2003;77:630-8.

24. Melanson EL, Cornier MA, Bessesen DH, Grunwald GK, MacLean PS, Hill JO. $24 \mathrm{H}$ metabolic responses to low- and high-intensity exercise in lean and obese humans. Obes Res 2006;14:180-2.

25. Schmitz KH, Hannan PJ, Stovitz SD, Bryan CJ, Warren $M$, Jensen MD. Strength training and adiposity in premenopausal women: strong, health, and empowered study. Am J Clin Nutr 2007;86:566-72.

26. Sanal E, Ardic F, Kirac S. Effects of aerobic or combined aerobic resistance exercise on body composition in overweight and obese adults: gender differences. A randomized intervention study. Eur J Phys Rehabil Med 2013;49:1-11.

27. Cullinen $K$, Caldwell M. Weight training increases fat-free mass and strength in untrained young women. J Am Diet Assoc 1998;98:414-8. http://dx.doi.org/10.1016/S00028223(98)00094-7.

28. Gibala MJ, McGee SL. Metabolic adaptations to shortterm high-intensity interval training: a little pain for a lot of gain? Exerc Sport Sci Rev 2008;36:58-63. http://dx.doi. org/10.1097/JES.0b013e318168ec1f.

29. Johannsen $N M$, Swift $D L$, Johnson $W D$, Dixit VD, Earnest $C P$, Blair SN, Church TS. Effect of different doses of aerobic exercise on total white blood cell (WBC) and WBC subfraction number in postmenopausal women: results from DREW. PloS One 2012;7:e31319. http://dx.doi.org/10.1371/journal.pone.0031319.

30. Mairbäurl H. Red blood cells in sports: effects of exercise and training on oxygen supply by red blood cells. Front Physiol 2013;4:1-13. http://dx.doi.org/10.3389/fphys.2013.00332. 